University of New Mexico

UNM Digital Repository

University Libraries \& Learning Sciences Faculty and Staff Publications

Academic Department Resources

2013

Culture and Online Distance Learning

Charlotte Nirmalani Gunawardena

Follow this and additional works at: https://digitalrepository.unm.edu/ulls_fsp

Part of the Online and Distance Education Commons 
Gunawardena, C. N. (2013). Culture and Online Distance Learning. In M. G. Moore (Ed.), Handbook of distance education ( ${ }^{\text {rd }}$ Edition) (pp. 185-200). New York, NY: Routledge.

\title{
Culture and Online Distance Learning
}

\author{
Charlotte N. Gunawardena
}

Online distance learning (ODL) has become a global phenomenon transcending national, political, and geographical boundaries challenging distance educators to reexamine notions of teaching and learning and issues of culture inherent in cross-border delivery of online courses and programs. Rogers, Graham and Mayes (2007) note that the sheer amount of learning content being developed in the West (defined for this chapter as Eurocentric, North American, Australasian) and exported via the Internet to other countries, highlights the crucial need to explore questions of culture more thoroughly in our online course designs to provide a more equitable learning experience for all. Global universities are faced with the choice between continuing to expect all students to adjust to traditional English-western academic values and uses of language, or changing their processes to accommodate others (Pincas, 2001).

Moore (2006) addresses the challenges and privileges that distance educators are faced within this context, and states that rather than addressing international students who have removed themselves from their own culture to be in the culture of the teacher, distance educators are now addressing students who remain physically and socially within their own culture, a culture that is foreign to, and mostly unknown to the teacher. The educational culture that is transmitted can be very different from the educational 
culture that adopts the program and can become a dominating force. Moore poses questions for us to consider such as: whose ideas are being shared or incorporated into the local culture, how will this incorporation affect the local culture, how does the instructor react to the student at a personal level, and how does the instructor integrate the student into the dominant culture of the online class. Carr-Chellman (2005) argues that making a single online course that is available worldwide is efficient, but culturally and contextually bankrupt. In order to make a product truly marketable globally, it is necessary to homogenize it. "Isn't learning necessarily contextualized in our own cultures and contexts?" (p. 9-10). The potential of ODL will be frustrated as long as educators in more technologically developed countries fail to understand the needs and perspectives of students in other countries, and the potential to learn from the perspectives of people in other countries will be lost for students in more technologically developed countries (Moore, Shattuck, and Al-Harthi, 2005). Therefore, in order to provide quality education to diverse audiences, distance educators need to be sensitive to hegemonic perspectives, "the imposition of cultural values and practices" (Latchem, 2005, p. 189), educational differences, and the social, cultural and language assumptions embedded in online courses and programs.

Several researchers have pointed out the dearth of studies on culture and ODL (Rogers, Graham, \& Mayes, 2007; Uzuner, 2009; Zawacki-Richter, 2009). This could be partly due to the fact that developing definitions of "culture" for the online context, framing questions related to culture, and conducting cross-cultural research studies are challenging. Zawacki-Richter (2009) in his Delphi study of research areas in distance education noted that the role of culture and cultural differences in global distance 
learning programs should receive much more attention.

This chapter examines the significance of culture and its impact on communication, and the teaching and learning process in ODL. I will begin by attempting to define culture for the online learning context and will explore cultural factors that impact learning, the sociocultural context, group process, language and discourse in ODL. I will conclude with a discussion of implications for designing ODL with culture in mind by presenting an instructional design model we developed that can be used to address cultural factors in learning design.

I address issues of culture, drawing on the emerging body of interdisciplinary research on globalization, the Internet, online learning, technology-based language learning, and virtual communities, and from my own previous discussion of culture and online distance education (Gunawardena \& La Pointe, 2007; Gunawardena \& La Pointe, 2008; Gunawardena, Wilson, \& Nolla, 2003), and research studies conducted in China, Mexico, Morocco, Spain, Sri Lanka, Turkey, and the United States.

\section{Defining Culture in the Context of Online Distance Learning (ODL)}

Many of the studies that have examined the role of culture in ODL (Gunawardena, et al., 2001; Moore, Shattuck, and Al-Harthi, 2005; Uzuner, 2009) have defined culture employing the four dimensions of nationally held cultural values: 'individualismcollectivism', 'power distance', 'uncertainty avoidance', and 'masculinity-femininity,' developed by Hofstede $(1980,1986)$ based on a factor analysis of business-oriented cultural values; and dimensions of contextual information, high and low context 
communication styles advanced by Hall (1973, 1990).

Ess (2009) provide a considered critique of the applicability of Hofstede's framework to the online context and note that what interests $\mathrm{CMC}$ researchers is how national, as well as other cultural identities such as ethnicity, youth culture, and gender, etc. interact with intercultural communication online; that is already removed from the face-to-face setting. Very often those who communicate online identify with multiple frames of reference. They note that Hofstede's framework (1980) and to a lesser extent Hall's $(1973,1990)$ conceptualization of culture appear to be limited to national cultural differences and thus less well-suited for understanding and researching the multiple cultural differences within nation-states, including the 'third' or hybrid identities that are themselves fostered by the cultural flows facilitated by the Internet and the web. Our research (Gunawardena, Idrissi Alami, Jayatilleke, \& Bouacharine, 2009) supported this view, by showing that although Sri Lankan and Moroccan societies would be classified in Hofstede's framework as high power distance societies, participants from these countries look to the online medium as a liberating medium that equalizes status differences, thereby providing them with a level playing field. Therefore, their interactions online will not necessarily reflect high power distance communication, even though their culture would be classified as high power distance. On the other hand, we found Hall's $(1973,1990)$ conceptualization of high context and low context communication styles, and implied indirect and direct communication styles, useful for analyzing cultural differences in communication online. Context is important to understanding a message and its connotations in both Moroccan and Sri Lankan cultures. Many Moroccans and Sri Lankans adopt indirect communication styles in face-to-face communication. 
Therefore, Hall's conceptualization helped us to analyze if there were changes in communication styles when participants interacted online, or whether they were using the same communication styles online as they would use face-to-face (Gunawardena et al., 2009).

Goodfellow and Hewling (2005), and Goodfellow and Lamy (2009), like Ess (2009) critique the essentialist frameworks developed by Hofstede and Hall to describe national cultural characteristics as inappropriate to understand culture in transnational online learning contexts. Goodfellow and Hewling (2005) move from an "essentialist" to a "negotiated" perspective to conceptualize culture as being negotiated in online discussions. This stance on seeing culture as negotiated is similar to Hall's definition of culture as communication "Culture is communication and communication is culture" (Hall, 1990, p. 186). Raffaghelli and Richieri (2012) note that "Networked learning should emphasize Bruner's idea about education as forum where culture is not transmitted but generated through interaction" (pp. 102-103) leading to new learning cultures.

Goodfellow and Lamy (2009) undertake the task of problematizing the very notion of 'culture' in connection with online learning environments and move on to develop the concept of "learning cultures" which takes account of the emergence of "new" cultural and social identities in virtual learning communities which draw on cybercultures of the Internet as well as systems of cultural relations inherited from conventional educational or corporate settings. They note that the emergence of 'learning cultures" might transcend both the institutional cultures of learning in which the resources originated and the cultural learning styles predominant in the sites where they 
were taken up: "It is characteristic of online learning cultures that the negotiation of personal and social identities is integral to learning, just as a critical awareness of culture is integral to a nonhegemonic model of online learning..."(p. 176), “The identities of participants become part of the knowledge constructed as well as the means of construction" (Goodfellow and Lamy, p. 176).

Therefore, one can come to terms with the complexity of culture in online courses, by defining it from the perspective of the Internet as a culture in its own right blurring the boundaries between the real and virtual worlds. Creating and participating in new communities is one of the primary pleasures people have interacting online, and these communities develop their own conventions for interaction, and for what is acceptable and not acceptable behavior online (Baym, 1995). "This web of verbal and textual significances that are substitutes for and yet distinct from the networks of meaning of the wider community binds users into a common culture whose specialized meanings allow the sharing of imagined realities" (Reid 1995, p. 183). Ess (2009) expands this line of thought further by exploring the notion that technology itself is culturally produced and thus is also a culturally shaped artifact in contrast to the notion that technology is culturally neutral or just a tool and hence its design and implementation requires no attention to its cultural origin. He discusses how digital environments can create "third cultures" where identity can be constructed and negotiated through interaction with other participants.

Thus, subscribing to a view of culture as negotiated online, I have adopted the definition of culture as an "idioculture," a concept developed by Gary Alan Fine and cited 
by Cole and Engestrom (2007), in my own work (Gunawardena et al., 2009) as an appropriate definition of culture online:

An idioculture is a system of knowledge, beliefs, behaviors, and customs shared by members of an interacting group to which members can refer and that serve as the basis of further interaction. Members recognize that they share experiences, and these experiences can be referred to with the expectation they will be understood by other members, thus being used to construct a reality for the participants (Fine, 1987, p.125).

This definition accommodates the idea of culture as a locally emerging activity system involving a briefer stretch of history (Cole \& Engestrom, 2007), and includes multiple cultural selves and hybrid identities on the Internet that interact with each other cross-culturally to form unique cultures of their own. The definition allows for the development of culture through dialogue, negotiation, and the sharing of experiences. The definition fits well with the ephemeral, fluid nature of the Internet which fuels the development of cybercultures, cultures that emerge among those who use the Internet to communicate, developing its own etiquette, norms, customs, ethics and mythology, just as an idioculture does.

With this understanding of culture online, I next explore a selection of research studies on culture and ODL.

\section{Research on Culture and Online Distance Learning (ODL)}


Although there are many ways in which culture impacts ODL, in the following section, I have selected to focus my discussion to examine how culture plays a role in (a) online learning specifically social construction of knowledge, (b) the sociocultural environment, specifically social presence and group process, and (c) language and discourse.

\section{Learners and preferred ways of learning.}

How one learns and what one learns is culturally determined. People reared in different cultures learn to learn differently (Matsumoto,1996; Merriam, 2007). Some do so by pattern drill, memory, and rote as explained by behaviorist theory; some work in groups learning through interaction with others to cross the zone of proximal development (Vygotsky, 1978). Generally, the primary theory of knowledge construction underlying most emerging online course designs emphasizes the exchange of ideas, expressions of agreement and disagreement to construct meaning.

Biesenbach-Lucas (2003), in her survey of the differences between native and non-native students in their perceptions of asynchronous discussions, found that both groups of students tended to avoid "challenge and explain cycles" where they had to do more than demonstrate knowledge by also agreeing and disagreeing in non-abrasive ways. She notes that non-native speakers, particularly students from Asian countries, consider it far less appropriate to challenge and criticize the ideas of others. In addition, they may not know how to express disagreement appropriately in English. This view is supported by Zhao and McDougall's (2008) when they note that Chinese students "may post fewer messages in online discussions, because they are not accustomed to discussion-based learning and hesitate to contradict their peers and instructors in a public 
forum" (p. 75). Cultures which value interpersonal harmony may refrain from critical comments in text conferencing to avoid tension and disagreement (Hu, 2005). Rye and Støkken (2012) made a similar observation in their study of online collaboration in a global master's program. They point out that the African (Ghanian and Ugandan) students were surprised by the Norwegian students' very direct and critical communication with the academic staff and fellow students, which was seen as impolite behavior in an academic setting. This situation made them uncomfortable, as respect for the teacher's authority is a deep-rooted value in most African societies. "Thus, the first months of global online collaboration was for many of the African students characterised by observation and by wondering about how they might be able to function as a real member of the online community" (p. 200). Biesenbach-Lucas notes that this lack of challenge and disagreement of ideas is troubling as it is the "resolution of such areas of agreement and disagreement that 'results in higher forms of reasoning' because 'cognitive development requires that individuals encounter others who contradict their own intuitively derived ideas." (p. 37).

The point we need to consider here is whether such challenges to ideas expressed by others in online discussions is a necessary condition for higher forms of reasoning and knowledge construction or whether it is merely an expectation from a western academic point of view, particularly American. Further, we should consider whether higher cognitive reasoning and knowledge construction can happen without such open disagreement of ideas. The following discussion of two studies from Mexico and Sri Lanka provide a different perspective. 
Lopez-Islas (2001) in his analysis of knowledge construction in online discussion forums at Monterrey Tech-Virtual University in Mexico using the Gunawardena, Lowe and Anderson's (1997) Interaction Analysis Model (IAM) that describes five phases in the process of knowledge construction; 1. Sharing, comparing and agreement, 2. cognitive dissonance or disagreement of ideas, 3 . negotiation of meaning and coconstruction of knowledge, 4. testing and modification of proposed co-construction, and 5) application of newly constructed meaning, observed that cognitive dissonance (phase two) was not evident in his data as open disagreement with ideas expressed by others is not appropriate in the Mexican cultural context. Participants moved to knowledge construction (phase 3) without moving through the cognitive dissonance phase as specified in the IAM model.

In our studies that employed the IAM model to examine the impact of crosscultural e-mentoring on social construction of knowledge in inquiry-based asynchronous discussion forums between American e-mentors and Sri Lankan protégés (Gunawardena, Skinner et al., 2008; and Gunawardena et al., 2011) we found a similar result. The Sri Lankan participants did not openly disagree at the level of ideas but moved to negotiation of meaning and co-construction of new knowledge based on consensus building. Therefore, we had to re-define 'dissonance' as specified in the IAM model in cultural terms. In further exploration of the online asynchronous interactions in the course, we found that while the academic discussion was very polite and lacked open disagreement of ideas, strong opinions and disagreements were expressed by the same participants in the informal "virtual canteen," where they engaged in a heated debate about gender issues. This finding made us reflect on the role of culture in academic online discussions. 
It is possible that collectivist traits in both the Sri Lankan and Mexican cultural contexts may have transferred to online group interaction in an academic setting where open disagreement of ideas would make the participants uncomfortable. Yet, it also shows that these very same participants as noted in the Sri Lankan context would engage in a heated debate in an informal discussion space. So, the context of the discussion, whether it was formal or informal is key to the expression of open disagreement. This is an interesting cultural difference that should be explored further in other online cross-cultural communication contexts.

Weinberger, Clark, Hakkinen, Tamura, and Fischer (2007) have observed the issues and challenges involved in argumentative knowledge construction in cross-cultural interactions, and state that there is little knowledge on the question of how learners from different cultures engage in and ultimately benefit from argumentative knowledge construction. They note that more research needs to be conducted on interaction patterns of collaborative learners within various cultures and propose examining the use of collaboration scripts that will support learners to engage in argumentative discussions.

From his study of a global e-mail debate on intercultural communication, Chen (2000) showed that differences in thinking patterns and expression styles influence student reactions to teaching methods. The debate format caused orientation problems for some participants as the "debate" is a product of low-context culture that requires a direct expression of one's argument by using logical reasoning. Students who come from highcontext cultures in Asia and Latin America find an argumentative format uncomfortable in an academic context, and this discomfort is exacerbated when the debate is facilitated through a medium devoid of non-verbal cues. Kim and Bonk (2002) in their cross- 
cultural comparisons of online collaboration between Korean, U.S. and Finnish students using the Curtis and Lawson's (2001) coding scheme, found differences in online collaborative behaviors: Korean students were more social and contextually driven online, Finnish students were more group-focused as well as reflective and, at times, theoretically driven, and U.S. students more action-oriented and pragmatic in seeking results or giving solutions.

Through in-depth online interviews, Shattuck (2005) attempted to understand how non-American students, primarily Asian, perceive the values related to study in an American distance learning program, and found that these students felt marginalized within the e-learning environment. She notes that online learning designs based on constructivist pedagogy and a high level of interaction can be a lonely and uncomfortable place for an international online learner whose cultural experience is different than the dominant educational culture (cited in Moore, Shattuck, \& Al-Harthi, 2005).

In our study using nine instruments to analyze preferred ways of learning in Hispanic adult learners in a Northern New Mexico community college (Sanchez \& Gunawardena, 1998), we found that these learners showed a preference for collaborative over competitive activities; reflectivity in task engagement; and a preference for an action-based, active approach to learning. For these learners, we recommended designing real world problem solving or case-based reasoning tasks in asynchronous learning environments that provide opportunities for reflection and active collaborative learning. In general, it is best to design alternative activities to reach the same objective and give students the option of selecting activities which best meet their culturally adapted ways of learning. 
Gibson (1998) makes a plea for understanding the distance learner in context (for example, in relation to classroom, peer group, workplace, family, culture and society) and the impact of their learning on those who share their lives in the multiple interacting contexts that contain them. "Our challenge as educators is to consider how the context might be seen as a partner in teaching and learner support." (p. 121). Based on their interviews with Ghanian, Ugandan, and Norwegian students on how the every day life of these students influence their participation in online collaboration in a global online master's program, Rye and Støkken (2012) showed the importance of recognizing the students' local context as a significant part of their educational space. Their exploratory case study showed how the influence of the students' local context creates an online learning space characterized by inequality. They note that how the local life of students interacts with their global interconnectedness has not yet been widely researched, although these relationships are increasingly characteristic of online higher education. Taking into consideration the local context, culture and needs as we design learning can avoid the trap of the dominant provider and the dependent receiver in online global programs (Mason, 1998).

\section{The Socio-Cultural Environment and Social Presence.}

Tu (2001) conducted a study of how Chinese perceive social presence in an online environment and found that three dimensions: social context, online communication, and interactivity affected Chinese students' perceptions of social presence, and observed that engaging Chinese students in a more interactive online learning environment will increase social presence. In addition, online privacy and public/private issues impacted 
the level of social presence. Chinese students perceived online communication as a more comfortable medium to express their thoughts due to lack of confrontation and facesaving concerns, but, on the other hand, they were concerned that their messages may appear in public areas that may cause them to lose face and privacy.

In a cross-cultural study of group process and development in online conferences in the United States (US) and Mexico, we (Gunawardena, et al., 2001) found that social presence emerged as a theme addressed by both US and Mexican focus group participants. US participants felt that social presence is necessary to the smooth functioning of a group, to provide a sense that the group members are real people. Social presence built trust and led to self-disclosure. Building relationships enhanced online civility. The Mexican focus group participants, however, felt that having personal information about the participants was unimportant. For these participants, how peers contribute to the conference is more important than knowing their personal information. The differences in the way that US participants and Mexican participants perceived social presence could be attributed to cultural differences related to power distance (Hofstede, 1980) in the two societies. In a high power distance society like Mexico, computermediated communication was seen as equalizing power and status differences present in society. Therefore, participants did not want their peers to interject social context cues that would take away the equalizing power of the online environment.

To further examine social presence from a cultural perspective, we undertook a study (Gunawardena, Bouachrine, Idrissi Alarmi, \& Jayatilleke, 2006) to generate a theoretical model of social presence from the perspective of two sociocultural contextsMorocco and Sri Lanka-by examining the communication conventions and processes 
employed by Internet chat users who develop online relationships with people they do not know. Employing qualitative ethnographic analysis and grounded theory building, this study explored cultural perspectives on "social presence" and properties related to the construct "social presence" in online communication. Preliminary results showed that social presence played a key role in the communication patterns of Internet chat users. Properties associated with social presence in both cultural contexts include: self disclosure, building trust, expression of identity, conflict resolution, interpretation of silence, and the innovation of language forms to generate immediacy.

Al-Harthi (2005) conducted in-depth telephone interviews with Arab students in order to understand how they perceived the values related to study in an American distance learning program, and found that for Arab students the lack of physical presence in the online environment was seen as a positive feature because, in addition to accessibility advantages recognizable to Western students, it provided a reduced risk of social embarrassment. Female Arab students in particular felt more comfortable studying online as it allowed for an easy conformity with the separation of genders that is traditional in Muslim culture. Moore (2006) notes that this sensitivity to what other people think is more foreign to American students, but for people of more collectivist (as contrasted with individualist) cultures, a form of communication that gives ways of saving face has value that may outweigh some of what the Western student might consider drawbacks. Al-Harthi's study identified several ways in which Arab students dealt with problems differently than their American colleagues. These findings provide insight into the social dynamic of ODL and the cultural factors we need to consider as we design. 


\section{Group Process and Conflict Resolution.}

Chan (2005), in his study of 59 tutors at the Open University of Hong Kong and their 1106 students, found that four dimensions: renqing (humanized obligation, carrying with it a continued expectation for mutual favor exchanges), face, harmony, and leadership, promoted group effectiveness. Tutors who brought face and saved face were considered more effective in creating harmony and balance in relationships. This study reflects the social obligation to help others within the social group.

In Morocco, communication patterns are more high context and less direct than in the United States. There are many taboos, and 'hchouma" - that can be translated as "shameful". Many questions do not get answered because Moroccans cannot be very direct and tell it to the face of the other. This opens up room for interpretation and sometimes miscommunication. (Gunawardena et al., 2009). The notion of "shame" was also a factor in Al-Harthi's (2005) study of Arab distance learners for whom guarding family reputation is key. One of the Arab female participants reported that she would log off an online discussion when joined by a fellow student who was acquainted with her family to avoid the risk saying anything that would reflect negatively on her family. This shows how social conventions that exist in the real world are also translated into online interaction.

In their study of synchronous chatting, Gunawardena, et al. (2006), noted that annonymity is a factor in the attempt to resolve conflict. If the person who insults is a stranger (and anonymous), either he or she will be ignored or insulted back. Cultural perceptions and social status seem to influence the way insults are handled. Attempts to 
resolve conflict depend on the strength of the relationship that has been built and the reality of the other. Face-saving strategies are adopted when there is a bond and when there is an interest in maintaining the relationship. If not, in the real-time world of chat, the general tendency is to close the window and forget the person. A study of face saving strategies employed in asynchronous online communication showed that all 16 participants representing six different ethnic groups would post a message in reply, saying that they had been misunderstood or that their discussion had been misinterpreted (Walsh, Gregory, Lake, \& Gunawardena, 2003). These studies show that attempts to resolve conflict are different in synchronous and asynchronous environments, and depend on the relationship that has been established.

\section{Language, and Discourse}

Martin and Nakayama (2003) distinguish language from discourse. While language refers to a method of communication, discourse refers to how language is used by particular groups of people, in particular contexts, and for particular purposes. The grammar of each language voices and shapes ideas, serving as a guide for people's mental activity, for analysis of impressions, and for synthesis of their mental stock in trade (Whorf, 1998). Language also reinforces cultural values and worldviews.

Although it is increasingly recognized as the international "langua franca" using English to learn, rather than one's native language, puts learners at a disadvantage. Often English is a learner's third or fourth language with little opportunity to actually use English daily. Communicating in English requires Asian and Arabic speakers to enter individual letters, one stroke at a time, on a keyboard while frequently referring to online 
dictionaries. English as a Second Language (ESL) learners need additional time for reading and need content provided in a variety of formats—written lectures, audio recordings, and concept maps.

Goodfellow and Lamy (2009) note that research into telecollaborative projects for language learning carries many stories of full or partial failure, not in the use of code (French, Spanish or Japanese, etc.) but in the partner's understandings of each others' cultural styles and genres. When computer users from different cultures communicate with each other they may not be aware of each other's genre (discourse type or discourse style) that is appropriate for the exchange. Kramsch and Thorne's study (2002) offers a good example of how miscommunication in an intercultural asynchronous online dialogue between American and French students was caused, not so much by deficient individual linguistic styles, but mostly by a lack of understanding "cultural genres" in each other's discourse.

In our study of informal synchronous chatting in Morocco and Sri Lanka, (Gunawardena et al., 2009), we found innovations in language forms to adapt to communication via chat. While the predominant language of chat in Morocco was French and in Sri Lanka, English, participants interjected the native language using the Latin keyboard to increases their level of social presence and connectedness when they were chatting with people who understood the native language. Chatters had developed unique forms of textual language and visual expressions to communicate their ideas and feelings through a new medium. Users bring with them the conventions of their native language, which embody cultural traits as well as their prior use of the second language, English or 
French. This implies that as online learning cultures develop, students and facilitators have to adjust to new modes of communication and interaction.

Smith (2005) found that a lack of awareness of cultural differences and generalizations about others who use English as a second language may enable learners from dominant cultures to unknowingly deauthorize group members with group coping strategies that, although well intended, limit opportunities for discussion. Groups assigned minimal responsibilities to their non-native English-speaking members because they felt these learners face unusual challenges of adapting to the United States and completing their studies. These non-native-English speakers then feel uncomfortable and unproductive. This crystallized the recognition of difference among group members; non-native speakers were perceived as "others" and treated as a threat to the group in ways that mirror hierarchical structures within larger society, creating unsafe learning spaces (Smith, 2005). Therefore, providing access to mainstream group discourse has to be managed diplomatically so as to not silence the voices of non-native speakers.

La Pointe and Barrett (2005), who taught English at a distance to Taiwanese and Mainland Chinese students found that although students recognize the need to study English through materials from the target culture, when they have no prior experience with the content of the materials, they cannot participate. When the topic was considered too far away, it did not generate the intended level of critical thinking as would a topic that more directly affect students' lives. This study showed that many students feared speaking English with native speakers. Students, particularly adults, seek a safe place to speak. The Internet provides that safe space through the removal of visual cues; informants reported that they are more willing to try to speak English when they cannot 
see either other students who they perceive to be better English speakers, or the teacher's dismay as they are speaking. They also feel safer participating from their homes.

\section{Implications for Designing Online Distance Learning (ODL)}

Moore (2006) asks: how to set up a course and manage it "so as to induce the different forms of understanding that lie in the culture represented by each student, to the greater benefit of the whole class?" (p. 4). Germain-Rutherford and Kerr (2008) review design guidelines for culturally inclusive online teaching and learning. Rogers, Graham, and Mayes (2007) examine the cultural competence of instructional designers. Parrish and Linder_VanBerschot (2010) developed the Cultural Dimensions of Learning Framework to address issues of culture when designing multicultural instruction. Given the discussion in this chapter of the myriad ways in which culture plays a role in online communication and learning, I now present an instructional design model that we developed and currently use to design online learning for diverse audiences.

The Wisdom Communities (WisCom) instructional design model that we developed (Gunawardena et al. 2006), and have used to design and deliver online graduate courses at US and Venezuelan universities, and an online faculty professional development program in Sri Lanka, is flexible in accommodating opportunities to design for cultural inclusivity. WisCom is most suitable for designing learning outcomes that require the exchange of multiple perspectives, problem solving, negotiation of meaning and social construction of knowledge, where there are no right or wrong answers. Based on sociocultural and socio-constructivist learning philosophies (Vygotsky, 1978) and 
distance education principles, WisCom aims to facilitate transformational learning by fostering the development of (a) a wisdom community, (b) knowledge innovation, (c) mentoring and learner support in an online learning environment, based on a "Cycle of Inquiry" module design, as recommended by Bransford et al. (2004) based on their research of how people learn. The Cycle of Inquiry module design mirrors authentic learning, and starts with a learning challenge which can be a question, a problem, or case to be solved, moving a group of learners through a process of exploration, gathering and sharing of resources and experience to address the learning challenge, discussing points of view with peers to learn from multiple perspectives, and concluding with the creation of a knowledge artifact (such as a concept map), that provides a solution to the learning challenge. This knowledge artifact is preserved in an online format for future learners. The cycle of inquiry helps learners to transform their perspectives through self-reflection and reflection on the community's learning process, which is documented in online journals. A detailed explanation and visual representation of the WisCom design model is found in Gunawardena et al. (2006). I discuss below how we have used WisCom to design culturally inclusive online learning.

\section{Developing a Wisdom Community}

Bleyl (2000), after an extensive review of literature from diverse cultural perspectives, concluded that wisdom appears to be an integration of cognition, affect, and reflectivity. Reflective learning is a significant aspect of perspective transformations, the instructional goal of the WisCom model. WisCom is community centered. Based on the notion that culture is created and negotiated online in a learning community and 
subscribing to the view of "idioculture" discussed earlier, we believe that in designing for cultural inclusivity, it is essential that we develop a learning culture that can take advantage of the diversity present among its members, a culture where each member has a voice. One of the initial activities the community undertakes is identity negotiation, where members have the option of either presenting oneself or another to the online community. Trust building, self-disclosure, and face negotiation were important aspects in the expression of identity and the generation of social presence (Gunawardena, et al., 2009). Self presentation is difficult and uncomfortable in many cultures, and therefore, in a cross-cultural telecollaboration we undertook with a Chinese university, we paired students so that the American students introduced the Chinese students, and vice versa, which overcame the difficulty the Chinese students had in presenting themselves online. Students either upload a photograph or an image that represents them. During the first two weeks students engage in community building activities and share and describe an important personal artifact.

To situate the learning context, the learning philosophy, and local flavor of the course, we adopt the metaphor of giftedness from the Keresan Pueblo communities in New Mexico as a core value, where giftedness (or the Western concept of intelligence) is defined as the individual's ability to contribute or "give back" to the well being of the entire community (Romero, 1994). The individual is seen in relationship to the learning community. In large classes, students work in peers support groups so that they have voice and opportunity to contribute. As Furstenberg, Levet, English, and Maillet (2001), have advocated we to try to make culturally hidden semantic networks explicit by structuring course discussions around enabling students to situate themselves in relation 
to others, to perceive similarities and differences in personal opinions and reactions within the group, and start identifying the many and complex factors influencing their attitudes so that they may become aware of how the content and manner of what they say is relevant to their immediate situation and to a given context. Communication protocols that describe how to participate in academic discussions, how language and discourse is used and negotiable and non-negotiable course and institutional expectations are clearly communicated at the beginning of the course. Guidelines are provided for leading and moderating online discussions to facilitate knowledge and community building. Social rules and conventions of communication are vital to understanding the norms according to which we carry out conversations and judge others. For instance, cultural variations in the use of silence might well lie behind lack of participation in online discussions. As Ishii and Bruneau (1994) have pointed out, the Japanese culture nurtures silence, reserve, and formality, whereas Western cultures place more value on speech, self-assertion, and informality.

When WisCom was implemented in an online faculty development forum in Sri Lanka, we found through our regression model that interaction (learner-learner and peer interaction) was a strong predictor of learner satisfaction among 53 participants explaining $50.2 \%$ of the variance in Learner Satisfaction (Gunawardena, Fernando, et al. 2007). This finding showed that if learning environments are designed for cultural inclusivity, then, interaction becomes a key vehicle for learning and satisfaction, thus dispelling the myth that South Asian students are reluctant to interact online.

\section{Mentoring and Learner Support}


WisCom utilizes mentoring as a mechanism for people supporting people as knowledge is created, and thereby contributing to building a community of wisdom. Mentoring aids in supporting new members and in the inclusion of diverse members into the community and diversity contributes new perspectives and wisdom to the community. Matching a novice or inexperienced learner with a more experienced counterpart facilitates the zone of proximal development (Vygotsky 1978), which refers to achieving a learner's optimal developmental potential, with assistance from an expert. Peer mentoring it utilized to support learning in peer groups and distributed e-mentoring brings in e-mentors from the community who share their expertise with specific groups or the entire class. In our study of cross-cultural e-mentoring, where American e-mentors supported social construction of knowledge in Sri Lankan protégés (Gunawardena et al. 2011), several e-mentor roles emerged, such as setting the context and expectations, facilitating and creating a momentum for the discussion, and facilitating of metacognitive activity amongst protégés. In addition to facilitation, there was evidence of the e-mentor taking a supportive role when issues arose with the technology used by groups. Ementors initiated the learning activity by setting the context and clearly defining the expectations even though they were based in a different country.

Learner support is designed to empower learners and honor diversity. Cultures differ in problem recognition, the problems for which help is sought, and attitudes and readiness to seek help. Understanding cultural and gender differences in help seeking enables us to design a learner support system that addresses diverse learner needs (Gunawardena and La Pointe, 2007). 


\section{Knowledge Innovation}

In online learning, a key feature of knowledge creation is discourse. Learners progress through the Cycle of Inquiry in WisCom exploring multiple perspectives through discourse. The Cycle of Inquiry utilizes the pre-existing knowledge of the learner by asking the learner to determine what they know and do not know about the learning challenge they have to address. This provides the opportunity for each learner to contribute his or her prior knowledge and perspectives. Through dialogue with the instructor, mentors, and peers, students are able to negotiate learning activities to reach the same objectives. The Cycle of Inquiry is flexible enough to balance learning activities and media formats to provide opportunities to learn in preferred ways and activities that challenge the learner to learn in new or less preferred ways. While social construction of knowledge is an important goal, challenges to other ideas, or open disagreement is not emphasized as crucial to knowledge construction. Learners negotiate within their peer groups, how they will address the learning challenge, the resources they will seek and share, and the type of collaborative activities they will engage in. Learning activities in the community are designed to develop a learning culture incorporating the diversity inherent in the class. Learners reflect on, share, and present their cultures' answers to problems through their chosen means - photos and videos, drawings, story telling, animation, song, scholarly text, poetry. Learners work in their small peer support groups to complete assigned tasks and reflect on the experience in the online journals. Course grades reflect contributions to both knowledge building and community building.

Exploratory studies conducted with graduate students in a Southwestern university in the United States in 2010, and in a Venezuelan university in 2005, and 2006, 
showed that the WisCom instructional design model was effective in building an online learning community, and supporting social construction of knowledge leading to transformative learning (Gunawardena and Layne, 2011). Additional research with diverse learners in various other cultural contexts is necessary to validate the efficacy of the WisCom design model.

I have presented one model that has helped me to design online learning for diverse audiences. However, what counts as sound educational practice in one context in all likelihood presents a form of cultural bias on the part of the person or institution promoting that educational practice. We as distance educators need to be cognizant of our own positionality, and communicate our world views clearly in our designs, and through rigorous evaluation and research determine which designs work best in specific contexts for specific learners. The field is wide open for quality research on questions of culture and online learning. I hope this chapter helps you to begin that quest.

\section{Acknowledgement:}

It is with deep gratitude that I acknowledge the significant contributions made by Deborah K. LaPointe (1952-2009) to our collaborative writing on issues of culture in previous publications.

\section{References}


Al-Harthi, A. S. (2005). Distance higher education experiences of Arab Gulf students in the United States: A cultural perspective. The International Review of Research in Open and Distance Learning, 6(3). Retrieved from http://www.irrodl.org/index.php/irrodl

Baym, N. K. (1995). The emergence of community in computer-mediated communication. In S. G. Jones (Ed.), CyberSociety: Computer-mediated communication and community (pp. 138-163). Thousand Oaks, CA: Sage.

Biesenbach-Lucas, S. (2003). Asynchronous discussion groups in teacher training classes: Perceptions of native and non-native students, Journal of Asynchronous Learning Networks, 7(3), 24-46. Retrieved from http:// sloanconsortium.org/publications/jaln_main

Bleyl, M. (2000). The wise ones: A multi-cultural perspective (unpublished doctoral dissertation). The University of New Mexico, Albuquerque, New Mexico.

Bransford, J., Vye, N., Bateman, H., Brophy, S., \& Roselli, B. (2004). Vanderbilt's AMIGO project: Knowledge of how people learn enters cyberspace. In T. M. Duffy \& J. R. Kirkley (Eds.), Learner-centered theory and practice in distance education: Cases from higher education (pp. 209-234). Mahwah, NJ: Lawrence Erlbaum.

Carr-Chellman, A. A. (Ed.). (2005). Introduction. In Global perspectives on e-learning: Rhetoric and reality (pp. 1-16). Thousand Oaks, CA: Sage.

Chan, B. (2005). From West to East: The impact of culture on personality and group dynamics. Cross Cultural Management, 12(1), 31-43. 
Chen, G. M. (2000). Global communication via Internet: An educational application. In G. M. Chen \& W. J. Starosta (Eds.), Communication and global society (pp. 143157). New York, NY: Peter Lang Publishing.

Cole, M. and Engestrom, Y. (2007). Cultural-historical approaches to designing for development, in J. Valsiner \& A. Rosa (Eds.), The Cambridge Handbook of Sociocultural Psychology (pp. 484-507). New York, NY: Cambridge University Press.

Ess, C. (2009). When the solution becomes the problem: Cultures and individuals as obstacles to online learning. In R. Goodfellow \& M. N. Lamy (Eds.), Learning cultures in online education (pp.15-29). London, UK: Continuum.

Fine, G. A. (1987). With the boys: Little League Baseball and preadolescent culture. Chicago, IL: University of Chicago Press.

Furstenberg G., Levet S., English K., \& Maillet K. (2001). Giving a virtual voice to the silent language of culture: the cultura project. Language Learning \& Technology, $5(1), 55-102$.

Germain-Rutherford, A., \& Kerr, B. (2008). An inclusive approach to online learning environments: Models and resources. Turkish Online Journal of Distance Education, 9(2), 64-85. Retrieved from https://tojde.anadolu.edu.tr/tojde30/index.htm

Gibson, C. C. (1998). The distance learner in context. In Distance learners in higher education: Institutional responses for quality outcomes (pp. 113-125). Madison, WI: Atwood Publishing. 
Goodfellow, R., \& Hewling, A. (2005). Reconceptualising culture in virtual learning environments: From an "essentialist" to a "negotiated" perspective, E-Learning, 2(4), 355-367. doi:10.2304/elea.2005.2.4.355

Goodfellow, R. \& Lamy, M. N. (Eds.). (2009). Learning cultures in online education. London, UK: Continuum.

Gunawardena, C. N., Bouachrine, F., Idrissi Alami, A., \& Jayatilleke, G. (2006, April). Cultural perspectives on social presence: A study of online chatting in Morocco and Sri Lanka. Paper presented at the Annual Meeting of the American Educational Research Association, San Francisco, CA.

Gunawardena, C. N., Fernando, S., Kulasekere, C., Lamontagne, M. D., Ekanayake, M. B., Thaiyamuthu, T., \& Jayatilleke, B. G. (2007, June). Online tutor mentor development through community building: A case study from a transitional nation. Paper presented at the Third International Conference on Open and Online Learning, Universiti Sains Malaysia, Penang, Malaysia.

Gunawardena, C. N., Idrissi Alami, A., Jayatilleke, G., \& Bouacharine, F. (2009). Identity, gender, and language in synchronous cybercultures: A cross-cultural study. In R. Goodfellow \& M. N. Lamy (Eds.), Learning cultures in online education (pp. 30-51). London, UK: Continuum.

Gunawardena, C. N., Keller, P. S., Garcia, F., Faustino, G. L., Barrett, K., Skinner, J. K., ... Fernando, S. (2011, December). Transformative education through technology: Facilitating social construction of knowledge online through crosscultural e-mentoring. In V. Edirisinghe (Ed.), Proceedings of The 1st 
International Conference on the Social Sciences and the Humanities, 1, 114-118. Peradeniya, Sri Lanka: Faculty of Arts, University of Peradeniya.

Gunawardena, C. N., \& LaPointe, D. (2007). Cultural dynamics of online learning. In M. G. Moore (Ed.), Handbook of distance education (2nd ed.) (pp. 593-607). Mahwah, NJ: Lawrence Erlbaum.

Gunawardena, C. N., \& LaPointe, D. (2008). Social and cultural diversity in distance education. In T. Evans, M. Haughey \& D. Murphy (Eds.), International handbook of distance education (pp. 51-70). Bingley, UK: Emerald.

Gunawardena, C. N., \& Layne, L. (2011, October). Building a knowledge-based society through online wisdom communities: An Instructional Design Model. Paper presented at the $24^{\text {th }}$ ICDE World Conference on Open and Distance Learning, Bali, Indonesia.

Gunawardena, C. N., Lowe, C. A., \& Anderson, T. (1997). Analysis of a global online debate and the development of an interaction analysis model for examining social construction of knowledge in computer conferencing. Journal of Educational Computing Research, 17(4), 395-429.

Gunawardena, C. N., Nolla, A. C., Wilson, P.L., López-Islas, J. R., RamírezAngel, N., \& Megchun-Alpízar, R. M. (2001). A cross-cultural study of group process and development in online conferences, Distance Education, 22, 85-121. Gunawardena, C. N., Ortegano-Layne, L., Carabajal, K., Frechette, C., Lindemann, K., Jennings, B. (2006). New model, new strategies: Instructional design for building online wisdom communities. Distance Education, 27(2), 217-232. 
Gunawardena, C. N., Skinner, J. K., Richmond, C., Linder-Van Berschot, J., LaPointe, D., Barrett, K., . . Padmaperuma, G. (2008, March). Cross-cultural e-mentoring to develop problem-solving online learning communities. Paper presented at the 2008 Annual Meeting of the American Educational Research Association, New York, NY.

Gunawardena, C. N., Wilson, P. L., \& Nolla, A. C. (2003). Culture and online education. In M. Moore \& B. Anderson (Eds.), Handbook of distance learning (pp. 753775). Mahwah, NJ: Lawrence Erlbaum.

Hall, E. T. (1973). The silent language. New York, NY: Anchor Book Editions.

Hall, E. T., \& Hall, M. R. (1990). Understanding cultural differences: Germans, French, and Americans. Yarmouth, Maine: Intercultural Press.

Hofstede, G. (1980). Culture's consequences: International differences in work-related values. Beverly Hills, CA: Sage.

Hofstede, G. (1986). Cultural differences in teaching and learning. International Journal of Intercultural Relations, 10(3), 301-320.

Hu, G. (2005). Using peer review with Chinese ESL student writers. Language Teaching Research, 9(3), 321-342.

Ishii, S., Bruneau, T. (1994). Silence and silences in cross-cultural perspective: Japan and the United States. In L. A. Samovar \& R. E. Porter (Eds.), Intercultural communication: A reader (7th. ed., pp. 246-251). Belmont, CA: Wadsworth.

Kim, K. \& Bonk, C. J. (2002) Cross-cultural comparisons of online collaboration, Journal of Computer Mediated Communication, 8(1). doi:10.1111/j.10836101.2002.tb00163. 
Kramsch, C., \& Thorne, S. (2002). Foreign language learning as global communicative practice. In D. Block \& D. Cameron (Eds.), Globalization and language teaching (pp. 83-100). London, UK: Routledge.

Lopez-Islas, J. R. (2001, December). Collaborative learning at Monterrey Tech-Virtual University. Paper presented at the Symposium on Web-based Learning Environments to Support Learning at a Distance: Design and Evaluation. Asilomar, Pacific Grove, California.

LaPointe, D., \& Barrett, K. (2005, May). Language learning in a virtual classroom: Synchronous methods, cultural exchanges. Paper presented at the meeting of Computer-Supported Collaborative Learning, Taipei, Taiwan.

Latchem, C. (2005). Towards borderless virtual learning in higher education. In A. A. Carr-Chellman (Ed.), Global Perspectives on e-learning: Rhetoric and reality (pp. 179-198). Thousand Oaks, CA: Sage.

Martin, J. N., \& Nakayama, T. K. (2004). Intercultural communication in contexts (3rd ed.), New York, NY: McGraw-Hill.

Mason, R. (1998). Globalising education: Trends and applications. London, UK: Routledge.

Matsumoto, D. (1996). Culture and psychology. Pacific Grove, CA: Brooks/Cole Publishing.

Merriam, S. B. and Associates (2007). Non-Western perspectives on learning and knowing. Malabar, FL: Krieger.

Moore, M. G. (2006). Questions of culture [Editorial]. The American Journal of Distance Education, 20, 1-5. 
Moore, M. G., Shattuck, K., \& Al-Harthi, A. (2005). Cultures meeting cultures in online distance education. Journal of e-Learning and Knowledge Society, 2(2). Retrieved from http://je-lks.maieutiche.economia.unitn.it/index.php /Je-LKS/index

Parrish, P., \& Linder-VanBerschot, J. A. (2010). Cultural Dimensions of Learning: Addressing the Challenges of Multicultural Instruction. International Review of Research in Open and Distance Learning, 11(2). Retrieved from http://www.irrodl.org/index.php/irrodl

Pincas, A. (2001). Culture, cognition, and communication in global education. Distance Education, 22, 30 .

Raffaghelli, J. E., \& Richieri, C. (2012). A classroom with a view: Networked learning strategies to promote intercultural education. In L. Dirckinck-Holmfeld, V. Hodgson, \& D. McConnell (Eds.), Exploring the Theory, Pedagogy and practice of networked learning (pp. 99-119). New York: Springer.

Reid, E. (1995). Virtual worlds: culture and imagination. In S. G. Jones (Ed.), CyberSociety: Computer-mediated communication and community (pp. 164-183). Thousand Oaks, CA: Sage.

Rogers, C., Graham, C. R., \& Mayes, C. T. (2007). Cultural competence and instructional design: exploration research into the delivery of online instruction crossculturally. Educational Technology Research and Development, 55, 197-217.

Romero, M. E. (1994). Identifying giftedness among Keresan Pueblo Indians: The Keres study. Journal of American Indian Education, 34(1), 35-58. 
Rye, S. A., \& Støkken, A. M. (2012). The implications of the local context in global online education. International Review of Research in Open and Distance Learning, 13(1), 191-206. Retrieved from http://www.irrodl .org/index.php/irrodl

Sanchez, I., \& Gunawardena, C. N. (1998). Understanding and supporting the culturally diverse distance learner. In C. Campbell Gibson (Ed.), Distance learners in higher education: Institutional responses for quality outcomes (pp. 47-64). Madison, WI: Atwood Publishing.

Shattuck, K. (2005). Cultures meeting cultures in online distance education: Perceptions of international adult learners of the impact of culture when taking online distance education courses designed and delivered by an American university (Unpublished doctoral dissertation). Pennsylvania State University, University Park, Pennsylvania.

Smith, R. O. (2005). Working with difference in online collaborative groups. Adult Education Quarterly, 55(3), 182-199.

Tu, C. H. (2001). How Chinese perceive social presence: An examination of interaction in online learning environment. Education Media International, 38(1), 45-60. doi:10.1080/09523980010021235

Uzuner, S. (2009). Questions of culture in distance learning: A research review. International Review of Research in Open and Distance Learning, 10(3), 1-19. Retrieved from http://www.irrodl.org/index.php/irrodl Vygotsky, L. S. (1978). Mind in society: The development of higher psychological processes. Cambridge, MA: Harvard University Press. 
Walsh, S. L., Gregory, E. M., Lake, M. Y., \& Gunawardena, C. N. (2003). Self-construal, facework, and conflict styles among cultures in online learning environments. Educational Technology Research and Development 51(4), 113-122.

Weinberger, A., Clark, D. B., Hakkinen, P., Tamura, Y., and Fischer, F. (2007). Argumentative knowledge construction in online learning environments in and across different cultures: a collaboration script perspective. Research in Comparative and International Education, 2(1), 68-79.

Whorf, B. (1998). Science and linguistics. In M. J. Bennett (Ed.), Basic concepts of intercultural communication: Selected readings (pp. 85-95). Yarmouth, ME: Intercultural Press.

Zawacki-Richter, O. (2009). Research areas in distance education: A delphi study. International Review of Research in Open and Distance Learning 10(3), pp. 117. Retrieved from http://www.irrodl.org/index.php /irrodl

Zhao, N., \& McDougall, D. (2008). Cultural influences on Chinese students' asynchronous online learning in a Canadian university. Journal of Distance Education, 22(2), 59-80. 